\title{
Genetic diversity of Colombian sheep by microsatellite markers
}

Ricardo Ocampo ${ }^{1 *}$, Henry Cardona ${ }^{1}$, and Rodrigo Martínez ${ }^{2}$

\section{ABSTRACT}

In Colombia the sheep production systems are managed under extensive conditions and mainly correspond to peasant production systems so their genetic management has led to increased homozygosity and hence productivity loss. The aim of this study was to determine the genetic diversity in 549 individuals corresponding to 13 sheep breeds in Colombia, using a panel of 11 microsatellite molecular markers. One hundred and fifty seven alleles were found (average of 14.27 alleles/locus), with a range of observed and expected heterozygosity from 0.44 to 0.84 and 0.67 to 0.86 , respectively. Thirty-three of 143 Hardy Weinberg tests performed showed significant deviations ( $p$ $<0.05$ ) due to a general lack of heterozygous individuals. The Fis ranged from 0.01 in Corriedale to 0.15 for the Persian Black Head breed, suggesting that there are presenting low to moderate levels of inbreeding. Overall, Colombian sheep showed high levels of genetic diversity which is very important for future selection and animal breeding programs.

Key words: DNA, genetic diversity, microsatellite, Colombian sheep.

\section{INTRODUCTION}

Sheep was one of the first cattle species in being domesticated, dating back around $9000 \mathrm{yr}$ ago. It is proposed that the sheep originated from at least three ancestral subspecies of wild mouflon, as inferred from multiple mitochondrial lineages (Guo et al., 2005; Chen et al., 2006; Chessa et al., 2009). Eventually human migration, climate change, and selection for different purposes increased the number of breeds around the world to more than 2455.

According to the latest sheep inventory made by the Colombian Agricultural Institute (ICA) in 2013, Colombia has a total population of 1142893 sheep, which are distributed throughout the country. The departments which showed increased activity in sheep production were the departments of Guajira, Magdalena, Córdoba, Cesar, and Santander, who combined account for roughly $80 \%$ of the national sheep inventory.

The genetic foundation of Colombian sheep is mainly of creole wool animals with European descent and creole hair animals (commonly known as "camuros") with African descent. These creole animals were brought into the country about $500 \mathrm{yr}$ ago during the conquest period. Up until now they have adapted to the harsh conditions of the Colombian tropics and have been characterized to be rustic, prolific, and resistant to ecto and endoparasites (Delgado et al., 2009).

Within Colombia it is possible to find various foreign animals which are brought mainly from Europe and other American countries. Some of the breeds include 'Katahdin', 'Santa Inés', 'Pelibuey', 'Dorset', 'Dorper', 'Hampshire', etc., which are preferred due to their growth performance compared with our creole animals but they do not have the same ability to adapt as well to the tropical conditions (Egito et al., 2002).

The globalization of production systems and competition between breeds has led to the disappearance of many native breeds in the world (Tapio et al., 2010). The Food and Agriculture Organization of the United Nations (FAO) has estimated that $36 \%$ of known sheep breeds in the world are either endangered or extinct (FAO, 2011).

On the other hand, the use of a few superior genetic males for intensive mating can result in the reduction of the effective population size, increase the levels of inbreeding in the population, and finally, reduce the levels of genetic diversity within breeds. This is crucial to maintain throughout the generations because without this, our options for reproduction and genetic improvement could 
be limited to the extent that the unpredictable needs of the future will not be able to be satisfied (Kantanen et al., 1999; Li et al., 2007).

The recent awareness campaigns for the conservation of genetic resources encouraged to carry out studies of genetic diversity in different breeds and species of livestock (Sodhi et al., 2006). Several studies have successfully used microsatellite molecular markers to characterize the genetic diversity between breeds and species of livestock ( $\mathrm{Li}$ et al., 2000; Baumung et al., 2006; Yang et al., 2008; Sollero et al., 2008; Arora et al., 2010; Kugonza et al., 2011; Dixit et al., 2012; Souza et al., 2012) because these markers have high polymorphism, co-dominant inheritance, abundance in the genome, selectively neutral behavior, easy access, and high reproducibility (Dodgson et al., 1997).

The aim of this study was to determine the genetic diversity of Colombian sheep populations using a panel of 11 microsatellite molecular markers, to use this information in conservation and genetic improvement plans of Colombian sheep populations.

\section{MATERIALS AND METHODS}

\section{Sampling}

Fresh blood samples from 549 unrelated sheep from 13 breeds were taken: 'Blackbelly' (BB), 'Camuro' (CAM), 'Corriedale' (CRRD), 'Wool Creole' (CRL), 'Dorper' (DP), 'Dorset' (DS), 'Hampshire' (HAM), 'Katahdin' (KT), 'Mora Colombiana' (MORO), 'Pelibuey' (PBY), 'Persian Black Head' (PCN), 'Romney Marsh' (ROM), and 'Santa Inés' (STI). Samples were taken from 56 farms located in 11 departments (Antioquia, Boyacá, Caldas, Cesar, Córdoba, La Guajira, Magdalena, Risaralda, Santander, Sucre, and Valle del Cauca). Each sample was taken according to the recommendations made by the Global project for the maintenance of domestic animal genetic diversity (MoDAD; FAO, 1995).

\section{DNA extraction and genotyping}

Genomic DNA of all samples was extracted from white blood cells using a commercial kit. Purity and concentration of each sample was quantified using a spectrophotometer (NanoDrop 2000, Thermo Scientific, Wilmington, Delaware, USA).

All microsatellites used in this study are part of a panel markers recommended by the International Society of Animal Genetics (ISAG)/FAO to study genetic diversity in sheep (FAO, 2011). These markers were selected by taking into account the level of polymorphism previously detected in other studies and the location on different chromosomes.

In this study a total of eleven microsatellite molecular markers were amplified using the polymerase chain reaction (PCR) technique: BM1824, ILSTS5, ILSTS11, ILSTS28, MCM140, MAF214, MAF33, OarCB2256, SRCRSP1, SRCRSP5, and SRCRSP9. The reverse sequence of each primer was labeled with fluorochromes 6-FAM, VIC, NED (Applied Biosystems, Foster City, California, USA) in its 5' end.

Microsatellite markers were grouped in two multiplex for its amplification, making sure that overlaps between the amplification products were avoided.

The final volume of the PCR mix was $10 \mu \mathrm{L}$ which contained 1X PCR buffer, $0.2 \mathrm{mM}$ of each deoxynucleotides (dNTPs), $0.2 \mu \mathrm{M}$ each primer, 1.85 U Hot Start Taq polymerase (ABM), $1.5 \mathrm{mM} \mathrm{MgCl} 2,1.14 \mu \mathrm{L} \mathrm{GC}$ Enhancer (Applied Biosystems), $1 \mu \mathrm{L}$ DNA ( $120 \mathrm{ng}$ ) and milliQ water to adjust the final volume.

The amplification of the microsatellite was performed in a PTC 100 thermal cycler (MJ Research Inc., Waltham, Massachusetts, USA) using the following temperature profile: initial denaturation at $95{ }^{\circ} \mathrm{C}$ for $5 \mathrm{~min}$, followed by 35 cycles of $1.15 \mathrm{~min}$ at $95^{\circ} \mathrm{C}, 45 \mathrm{~s}$ at $55^{\circ} \mathrm{C}$, and $1 \mathrm{~min}$ at $72{ }^{\circ} \mathrm{C}$; and the final extension for $10 \mathrm{~min}$ at $72{ }^{\circ} \mathrm{C}$.

The amplified products generated by PCR were analyzed by capillary electrophoresis using a genetic analyzer (310 Genetic Analyzer, Applied Biosystems). For the analysis a 500 LIZ internal lane size marker (500 bp; Applied Biosystems) was used and the program GeneMapper 4.1 (Applied Biosystems) was used to determine the allele size of each of the 549 samples analyzed.

\section{Statistical analysis}

The allele frequencies for all loci, observed (Na) and effective number of alleles $(\mathrm{Ne})$ per locus, expected $(\mathrm{He})$ and observed heterozygosity (Ho) and exclusion power (Ep) for each marker were estimated using the GenAIEx 6.5 software (Peakall and Smouse, 2012).

The polymorphic information content (PIC) for each marker was estimated using the Excel Microsatellite Toolkit V 3.1.1 (Park, 2001) program.

Exact tests for deviations from Hardy Weinberg equilibrium (HW) by breed were estimated using Monte Carlo simulations via Markov chains with the software Genepop 4.2 (Rousset, 2008).

The population structure was analyzed by Wright's $\mathrm{F}$ statistics $\left(\mathrm{F}_{\mathrm{is}}, \mathrm{F}_{\mathrm{it}}\right.$, and $\left.\mathrm{F}_{\mathrm{st}}\right)$ as proposed by Weir and Cockerham (1984) using the program FSTAT version 2.9.3.2 (Goudet, 2002). To estimate the significance of rates, random permutations of genotypes among samples (Jackknifing) were used.

Two methods were used to analyze genetic differentiation. First, the Nei's standard genetic distance (Nei, 1987) was estimated with GenAIEx 6.5 software to define the genetic differences among the 13 breeds analyzed. The genetic distance values were used to construct a consensus tree using the algorithm Unweighted Pair Group Method using Arithmetic averages (UPGMA) with MEGA software version 6 (Tamura et al., 2013).

Second, the structure of the population and the degree of mixing were estimated using a model of Bayesian clustering of the program STRUCTURE (Pritchard et al., 2000). The 
program estimates, using multiple loci genotypes to assign individuals to populations, individual mix proportions and deducts the number of parental populations $(\mathrm{K})$ for a given sample. As suggested by several authors, the analysis included a mixture model with correlated allele frequencies (Pritchard et al., 2000; Zuccaro et al., 2008; Ciani et al., 2013).

To obtain a representative $\mathrm{K}$ value, 13 independent runs for each $\mathrm{K}(1 \leq \mathrm{K} \leq 13)$ were performed. For all runs a burn-in period of 200000 generations followed by 1000000 interactions MCMC (Markov Chain Monte Carlo) was adopted. The most likely number of clusters or $\mathrm{K}$ (populations or breeds) present in the data set was calculated with the $\Delta \mathrm{K}$ algorithm proposed by Evanno et al. (2005).

\section{RESULTS AND DISCUSSION}

\section{Genetic diversity of the general population}

For the entire sheep population a total of 157 alleles were found in 549 animals genotyped for the 11 microsatellite loci. The number of alleles varied from 10 for loci SRCRSP5 and SRCRSP9 to 23 for the locus ILSTS28. We found an average of 14.27 alleles per locus, a value that is slightly higher than the 13.53 alleles per locus found by Zhong et al. (2010) in a population of 584 sheep (10 breeds) in China using 19 microsatellite markers. Several measures of genetic diversity estimated for each locus in the entire sheep population are shown in Table 1.

The expected heterozygosity $(\mathrm{He})$, which is considered the best estimator of genetic diversity in the population (Kim et al., 2002), ranged from 0.67 for the locus ILSTS5 to 0.86 for the locus MAF33. The He average was 0.77 for the entire sheep population, a value that indicates that overall Colombian sheep population has a high genetic diversity. On the other hand, observed heterozygosity (Ho) ranged from 0.44 for SRCRSP5 locus to 0.84 for ILSTS28 locus. The Ho average was 0.68 for the 11 loci analyzed in the population. It is observed that in all cases Ho was less than He, except for the loci SRCRSP9 and ILSTS28 loci where it was higher. Similar results were found by Bozzi et al. (2009), Zhong et al. (2010), and Gornas et al. (2011), in sheep populations of Italy, China, and Sudan, respectively.

Polymorphic information content (PIC) for each marker ranged from 0.65 for the marker MAF 214 to 0.90 for the marker OarCB2256. The overall average for the 11 microsatellite loci was 0.74 and no marker showed PIC less than 0.5 indicating that all loci were highly polymorphic. The high values of PIC and the high average number of alleles per locus indicate that the panel of 11 microsatellite molecular markers used in this research project is suitable for studies of genetic diversity in Colombian sheep, besides genetic linkage studies (Kayang et al., 2002).

Exclusion power (EP) of each marker ranged from 0.45 for ILSTS5 to 0.72 for OarCB2256 and MAF33 markers. When EP of the 11 molecular markers used were combined we got a EP higher than $99.999 \%$, which indicates that it is practically impossible to assign a false paternity using this panel of microsatellite markers in sheep.

The differences in the population structure evaluated by the Wright's fixation index showed that the average $F_{\text {is }}$ value, which describes the excess or deficit of heterozygotes within subpopulations (breeds in our case) was 0.09 ( $\mathrm{p}<0.05)$ and therefore different from zero. Various markers such SRCRSP5, BM1824, MAF 214, and ILSTS11 showed Fis values of $0.40,0.22,0.18$, and 0.16 , respectively, indicating that there is an excess of homozygous individuals in the subpopulations for these markers. The other remaining markers showed values below of 0.10 .

The $\mathrm{F}_{\text {it }}$ fixation index, which measures the heterozygosity loss of the individual with respect to the overall population, was $0.13(\mathrm{p}<0.05)$, indicating that there are a general lack of heterozygous individuals in the country's sheep population of $13 \%$. The $\mathrm{F}_{\mathrm{st}}$ index which measures the degree of genetic diversity explained by differences between breeds was 0.04 . It is clear that the total genetic variation mostly corresponds to differences among individuals (96\%) and only $4 \%$ is the result of differences between breeds. This result indicates that genetic variation measured by microsatellites markers showed a low degree of genetic differentiation among subpopulations or breeds.

Similar results were reported by Bozzi et al. (2009), Zhong et al. (2010), Álvarez et al. (2012), Ben Sassi-Zaidy et al. (2014),

Table 1. Number of alleles (Na), effective number of alleles (Ne), observed heterozygosity (Ho), expected heterozygosity (He), polymorphic information content (PIC), exclusion power (EP), exclusion power accumulated (EP Accum), and F statistics ( $F_{\text {is }}, F_{\text {st }}$, $F_{\text {it) }}$ per locus.

\begin{tabular}{|c|c|c|c|c|c|c|c|c|c|c|}
\hline Locus & $\mathrm{Na}$ & $\mathrm{Ne}$ & Ho & $\mathrm{He}$ & $\mathrm{PIC}$ & EP & EP Accum & $\mathrm{F}_{\text {is }}$ & $\mathrm{F}_{\mathrm{st}}$ & $\mathrm{F}_{\text {it }}$ \\
\hline OarCB 2256 & 21 & 6.53 & 0.77 & 0.85 & 0.90 & 0.72 & 0.72 & 0.07 & 0.03 & 0.10 \\
\hline MAF 33 & 13 & 7.01 & 0.83 & 0.86 & 0.84 & 0.72 & 0.92 & 0.02 & 0.03 & 0.05 \\
\hline ILSTS 28 & 23 & 5.49 & 0.84 & 0.82 & 0.80 & 0.66 & 0.97 & -0.05 & 0.03 & -0.02 \\
\hline ILSTS 11 & 14 & 5.38 & 0.67 & 0.81 & 0.80 & 0.64 & 0.99 & 0.16 & 0.04 & 0.19 \\
\hline MCM 140 & 13 & 5.09 & 0.70 & 0.80 & 0.81 & 0.62 & 0.99 & 0.11 & 0.04 & 0.14 \\
\hline BM1824 & 11 & 4.63 & 0.61 & 0.78 & 0.75 & 0.58 & 0.99 & 0.22 & 0.03 & 0.24 \\
\hline SRCRSP 1 & 14 & 3.70 & 0.69 & 0.73 & 0.69 & 0.51 & 0.99 & 0.02 & 0.05 & 0.07 \\
\hline SRCRSP 5 & 10 & 3.73 & 0.44 & 0.73 & 0.69 & 0.50 & 0.99 & 0.40 & 0.01 & 0.40 \\
\hline SRCRSP 9 & 10 & 3.55 & 0.80 & 0.72 & 0.68 & 0.50 & 0.99 & -0.18 & 0.09 & -0.08 \\
\hline MAF 214 & 12 & 3.31 & 0.56 & 0.70 & 0.65 & 0.46 & 0.99 & 0.18 & 0.04 & 0.21 \\
\hline ILSTS 5 & 16 & 3.02 & 0.60 & 0.67 & 0.66 & 0.45 & 0.99 & 0.09 & 0.03 & 0.11 \\
\hline Mean & 14.27 & 4.68 & 0.68 & 0.77 & 0.74 & - & - & $0.09^{*}$ & $0.04^{*}$ & $0.13^{*}$ \\
\hline
\end{tabular}

* $\mathrm{p}<0.05$. 
and who reported $F_{\text {st }}$ ranges between 0.30 and 0.09 . The genetic similarities between sheep breeds in Colombia are probably due to the interbreeding between populations, as a result of the sires flow between farms and also due to the lack of control in cross-breeding between individuals within sheep farms.

\section{Genetic diversity between breeds}

With regards to breeds, the average number of alleles per locus was 7.08. The highest number of alleles per locus was found in the creole hair sheep or CAM (11.91 alleles per locus), value that is higher than the 7.80 alleles per locus reported by Quiroz et al. (2007) in Mexican creole sheep, 7.25 alleles per locus reported by Ochipinti et al. (2012) in Paraguayan creole sheep, and 7.71 alleles per locus reported by Blackburn et al. (2011) in North American creole sheep. However, we should consider that the high number of alleles found in the Colombian CAM may have arisen as a result of having taken samples of 292 individuals, which represent $53.18 \%$ of all individuals in the sample and it is because this breed is the most representative and common within the country since CAM represent over $50 \%$ of the national sheep inventory (Arcos et al., 2002). On the other hand, the lowest number of alleles per marker was found in the MORO breed (5.27 alleles per marker), a number that seems low but we only took eight samples of this breed due to its status of endangered. Moreover, the number of alleles per marker for this breed was higher than the 4.50 alleles per locus reported by McClean et al. (2011) for the Barbados Blackbelly breed. Several measures of genetic diversity for each breed are shown in Table 2.

The lowest Ho was presented in STI (0.63) and higher in HAM (0.74), while He showed the lowest value in MORO (0.70) and the highest in CAM (0.75). He and Ho do not differ widely among breeds, PCN showed the highest difference and ROM the lowest. In general, all breeds showed high genetic diversity for all loci analyzed.

Hardy Weinberg equilibrium tests for each breed from 11 microsatellites markers analyzed showed significant deviations $(\mathrm{p}<0.05)$ in 33 of $143 \mathrm{HW}$ tests performed
(Table 3), which is due to the heterozygote deficit in each breed. It was noted that only two breed ('Hampshire' and 'Mora Colombiana') of the 13 evaluated did not presented heterozygous deficit. The heterozygous deficit in the 11 remaining breeds can be attributed to several factors, including inbreeding and selection.

Estimated inbreeding $\left(\mathrm{F}_{\text {is }}\right)$ for each breed had an average value of 0.08 , ranging from 0.01 for CRRD to 0.15 for $\mathrm{PCN}$. All breeds showed $F_{\text {is }}$ values above zero indicating that there is a general deficit of individual heterozygous in each breed. Among the causes of this heterozygous deficit in breeds could be inbreeding (mating between related individuals) and selection (Álvarez et al., 2012) and the presence of population substructure (Wahlund effect) (Nei, 1987).

However, the main cause of the heterozygous deficit in the investigated sheep populations can be attributed to the inbreeding. Within the most visited farms in the investigation, inbreeding resulted from the lack of control in mating between animals which led to a lot of mating between related individuals, thus, eventually leading to the heterozygous reduction in the populations (Martínez et al., 2010).

Table 2. Number of individuals $(\mathrm{N})$, average number of alleles (Na), effective number of alleles ( $\mathrm{Ne}$ ), observed (Ho) and expected (He) heterozygosity, and $F_{\text {is }}$ value for each breed.

\begin{tabular}{lrrcccc}
\hline Breed & $\mathrm{N}$ & $\mathrm{Na}$ & $\mathrm{Ne}$ & $\mathrm{Ho}$ & $\mathrm{He}$ & $\mathrm{F}_{\text {is }}$ \\
\hline BB & 27 & 7.36 & 3.70 & 0.65 & 0.72 & 0.11 \\
CAM & 292 & 11.91 & 4.43 & 0.67 & 0.75 & 0.11 \\
CRRD & 15 & 5.82 & 3.64 & 0.73 & 0.71 & 0.01 \\
CRL & 23 & 7.09 & 4.07 & 0.68 & 0.73 & 0.10 \\
DP & 22 & 6.18 & 3.99 & 0.67 & 0.73 & 0.10 \\
DS & 15 & 6.09 & 4.08 & 0.70 & 0.72 & 0.07 \\
HAM & 14 & 6.18 & 3.96 & 0.74 & 0.72 & 0.02 \\
KT & 47 & 8.91 & 3.97 & 0.72 & 0.73 & 0.03 \\
MORO & 8 & 5.27 & 3.79 & 0.65 & 0.70 & 0.14 \\
PBY & 14 & 6.00 & 3.67 & 0.72 & 0.71 & 0.02 \\
PCN & 21 & 7.27 & 4.39 & 0.65 & 0.74 & 0.15 \\
ROM & 32 & 7.27 & 3.74 & 0.70 & 0.71 & 0.03 \\
STI & 19 & 6.64 & 3.64 & 0.63 & 0.71 & 0.13
\end{tabular}

BB: Blackbelly; CAM: Camuro; CRRD: Corriedale; CRL: Criolla de Lana; DP: Dorper; DS: Dorset; HAM: Hampshire; KT: Katahdin; MORO: Moro Colombiano; PCN: Persian Black Head; PBY: Pelibuey; ROM: Romney Marsh; STI: Santa Inés.

Table 3. Hardy Weinberg equilibrium test by breed.

\begin{tabular}{|c|c|c|c|c|c|c|c|c|c|c|c|}
\hline Breed & OarCB 2256 & MAF 33 & ILSTS 28 & ILSTS 11 & MCM 140 & $\mathrm{Bm} 1824$ & SRCRSP 1 & SRCRSP 5 & SRCRSP 9 & MAF 214 & ILSTS 5 \\
\hline BB & $0.01^{*}$ & 0.99 & $0.03^{*}$ & 0.58 & $0.00^{*}$ & 0.07 & 0.10 & $0.03^{*}$ & 0.18 & $0.04^{*}$ & $0.00^{*}$ \\
\hline CAM & $0.00^{*}$ & $0.00^{*}$ & $0.00^{*}$ & $0.00^{*}$ & $0.00^{*}$ & $0.00^{*}$ & 0.08 & $0.00^{*}$ & $0.00^{*}$ & $0.00^{*}$ & 0.95 \\
\hline CRRD & 0.79 & 0.50 & 0.38 & $0.02^{*}$ & 0.65 & 0.53 & 0.43 & 0.13 & 0.38 & 0.24 & 0.47 \\
\hline CRL & $0.00^{*}$ & 0.58 & 0.49 & 0.53 & 0.79 & 0.63 & 0.41 & $0.00^{*}$ & 0.32 & 0.88 & 0.98 \\
\hline DP & 0.99 & 0.19 & 0.94 & 0.12 & 0.26 & 0.10 & 0.97 & $0.00^{*}$ & 0.14 & 0.68 & 0.29 \\
\hline DS & 0.28 & 0.23 & 0.53 & 0.56 & 0.24 & $0.01^{*}$ & 0.86 & 0.12 & 0.53 & 0.99 & 0.10 \\
\hline HAM & 0.39 & 0.92 & 0.12 & 0.77 & 0.06 & 0.36 & 0.97 & 0.56 & 0.08 & 0.95 & 0.48 \\
\hline KT & 0.86 & 0.93 & 0.65 & $0.04^{*}$ & 0.43 & 0.06 & 0.99 & $0.00^{*}$ & 0.56 & $0.03^{*}$ & 0.99 \\
\hline MORO & 0.67 & 0.59 & 0.12 & 0.45 & 0.72 & 0.16 & 0.82 & 0.19 & 0.23 & 0.18 & 0.99 \\
\hline PBY & 0.58 & 0.72 & 0.94 & 0.49 & 0.42 & 0.96 & 0.99 & 0.46 & 0.79 & 0.55 & $0.00^{*}$ \\
\hline $\mathrm{PCN}$ & 0.76 & 0.93 & 0.69 & $0.01^{*}$ & 0.70 & $0.00^{*}$ & 0.77 & 0.08 & 0.15 & $0.00^{*}$ & 0.13 \\
\hline ROM & $0.01^{*}$ & 0.27 & 0.95 & 0.10 & 0.88 & $0.02^{*}$ & 0.78 & 0.27 & 0.72 & 0.96 & 0.90 \\
\hline STI & 0.18 & 0.44 & $0.02^{*}$ & 0.22 & $0.00^{*}$ & $0.01^{*}$ & 0.08 & $0.01^{*}$ & 0.75 & 0.80 & 0.73 \\
\hline
\end{tabular}

*Significant deviation from Hardy Weinberg equilibrium $(\mathrm{p}<0.05)$.

BB: Blackbelly; CAM: Camuro; CRRD: Corriedale; CRL: Criolla de Lana; DP: Dorper; DS: Dorset; HAM: Hampshire; KT: Katahdin; MORO: Moro Colombiano; PCN: Persian Black Head; PBY: Pelibuey; ROM: Romney Marsh; STI: Santa Inés. 
On the other hand most of production systems in the country have one or two sires to mate with all the females of the herd, which could reduce significantly the genetic diversity in the populations and contribute to the reduction of heterozygous individuals in the population (Tolone et al., 2012).

The matrix of Nei's standard genetic distance between breeds is represented in Table 4 and the corresponding phylogenetic tree is present in Figure 1.

The Nei's standard genetic distance ranged from 0.07 between CAM and KT to 0.42 between DP and PBY. Three different clusters were identified. The first is composed by CAM, KT, PCN, BB, and PBY breeds which are characterized for being hairy sheep which originated in Africa (or from African sheep descent) except KT, which was created in North America but for its creation Caribbean hair sheep were used (Álvarez et al., 2012). These breeds are the most widely distributed in tropical areas of the country and it is very common that most farms have individuals corresponding to these breeds and their $F_{1}$ crosses with the aim of increasing some production parameters in the offspring (Barrios, 2005).

The second cluster is composed by ROM, CRRD, CRL, MORO, and HAM, which are wool breeds of European

Figure 1. Phylogenetic tree (UPGMA) representing Nei's standard genetic distances between 13 sheep breeds in Colombia.

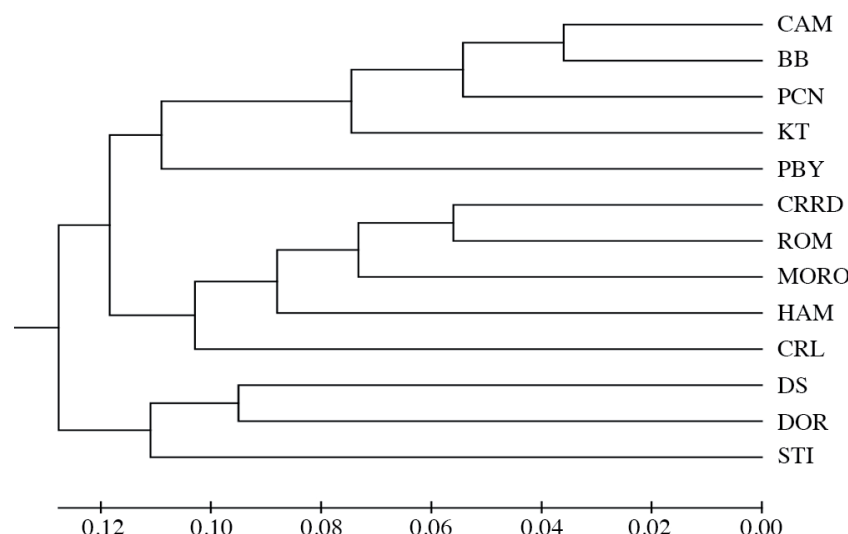

BB: Blackbelly; CAM: Camuro; CRRD: Corriedale; CRL: Criolla de Lana; DP: Dorper; DS: Dorset; HAM: Hampshire; KT: Katahdin; MORO: Moro Colombiano; PCN: Persian Black Head; PBY: Pelibuey; ROM: Romney Marsh; STI: Santa Inés. origin or descent (although CRRD breed comes from New Zealand, it was a cross-breed between European breeds such as 'Merino' and 'Lincoln'), and in Colombia inhabit highland tropical areas. It can be seen in the second cluster that although ROM and CRRD breeds are grouped in the same node, these breeds have different ancestral and geographical origins. Furthermore, according to sheep farmers and experts in Colombia these breeds converge in similar regions so it is common that mating among them has made it phenotypically difficult to distinguish one breed from another.

Colombian creole wool sheep CRL and MORO within the Colombian production systems are quite commonly used as the maternal breed for cross-breeding with CRRD, ROM, HAM, etc., in order to achieve an $\mathrm{F}_{1}$ with better performance parameters and good adaptability to the conditions of high tropics, because of this there has been a high level of introgression of foreign breeds within the Colombian creole wool sheep population (Martínez et al., 2010).

The third cluster is composed by DP, DS, and STI breeds. Although these breeds have different geographic origins, it is important to highlight that DP was created in South Africa due to crossing of DS and PCN breeds (Soma et al., 2012). Therefore the results of the distance matrix and phylogenetic tree are consistent with the geographical location, breeds origin history, and the nurturing practices that genetically improve the individuals (interbreeding).

The population structure was analyzed using the STRUCTURE program with the expected number of clusters (K) ranging from 1 to 13 . According with the method proposed by Evanno et al. (2005) it was assumed that $\mathrm{K}=3$ is the most likely number of ancestral populations that contribute to the genetic diversity observed in Colombian sheep breeds. No value of $\mathrm{K}$ showed a clear differentiation of any breed in a specific cluster and as the number $\mathrm{K}$ increases more complex patterns of mixture are observed (Figure 2), proving that the Colombian sheep populations are very mixed.

This can be considered as the introgression between the proportions of genetic material derived from three ancestral populations, as evidenced by the most probable $\mathrm{k}$ value. The first ancestral population may be comprised of African sheep that were brought to America by the colonists and merchants, who derived the creole hair sheep CAM, BB, PBY, and PCN

Table 4. Matrix of Nei's standard genetic distance between breeds.

\begin{tabular}{|c|c|c|c|c|c|c|c|c|c|c|c|c|}
\hline & BB & CAM & CRRD & CRL & DP & DS & HAM & KT & MORO & PBY & PCN & ROM \\
\hline CAM & 0.08 & & & & & & & & & & & \\
\hline CRRD & 0.32 & 0.23 & & & & & & & & & & \\
\hline CRL & 0.227 & 0.153 & 0.156 & & & & & & & & & \\
\hline DP & 0.307 & 0.249 & 0.234 & 0.266 & & & & & & & & \\
\hline DS & 0.334 & 0.230 & 0.234 & 0.176 & 0.222 & & & & & & & \\
\hline HAM & 0.325 & 0.267 & 0.242 & 0.164 & 0.249 & 0.272 & & & & & & \\
\hline KT & 0.168 & 0.072 & 0.182 & 0.141 & 0.211 & 0.181 & 0.236 & & & & & \\
\hline MORO & 0.302 & 0.235 & 0.207 & 0.175 & 0.303 & 0.344 & 0.219 & 0.219 & & & & \\
\hline PBY & 0.275 & 0.182 & 0.281 & 0.229 & 0.418 & 0.336 & 0.320 & 0.210 & 0.333 & & & \\
\hline PCN & 0.197 & 0.087 & 0.277 & 0.168 & 0.248 & 0.285 & 0.248 & 0.130 & 0.210 & 0.205 & & \\
\hline ROM & 0.300 & 0.187 & 0.112 & 0.137 & 0.265 & 0.224 & 0.198 & 0.161 & 0.146 & 0.179 & 0.193 & \\
\hline STI & 0.218 & 0.183 & 0.248 & 0.176 & 0.222 & 0.190 & 0.253 & 0.161 & 0.254 & 0.338 & 0.264 & 0.197 \\
\hline
\end{tabular}

BB: Blackbelly; CAM: Camuro; CRRD: Corriedale; CRL: Criolla de Lana; DP: Dorper; DS: Dorset; HAM: Hampshire; KT: Katahdin; MORO: Moro Colombiano; PCN: Persian Black Head; PBY: Pelibuey; ROM: Romney Marsh; STI: Santa Inés. 
Figure 2. Population structure estimated with STRUCTURE in 13 sheep breeds in Colombia for K values from 2 to 5.
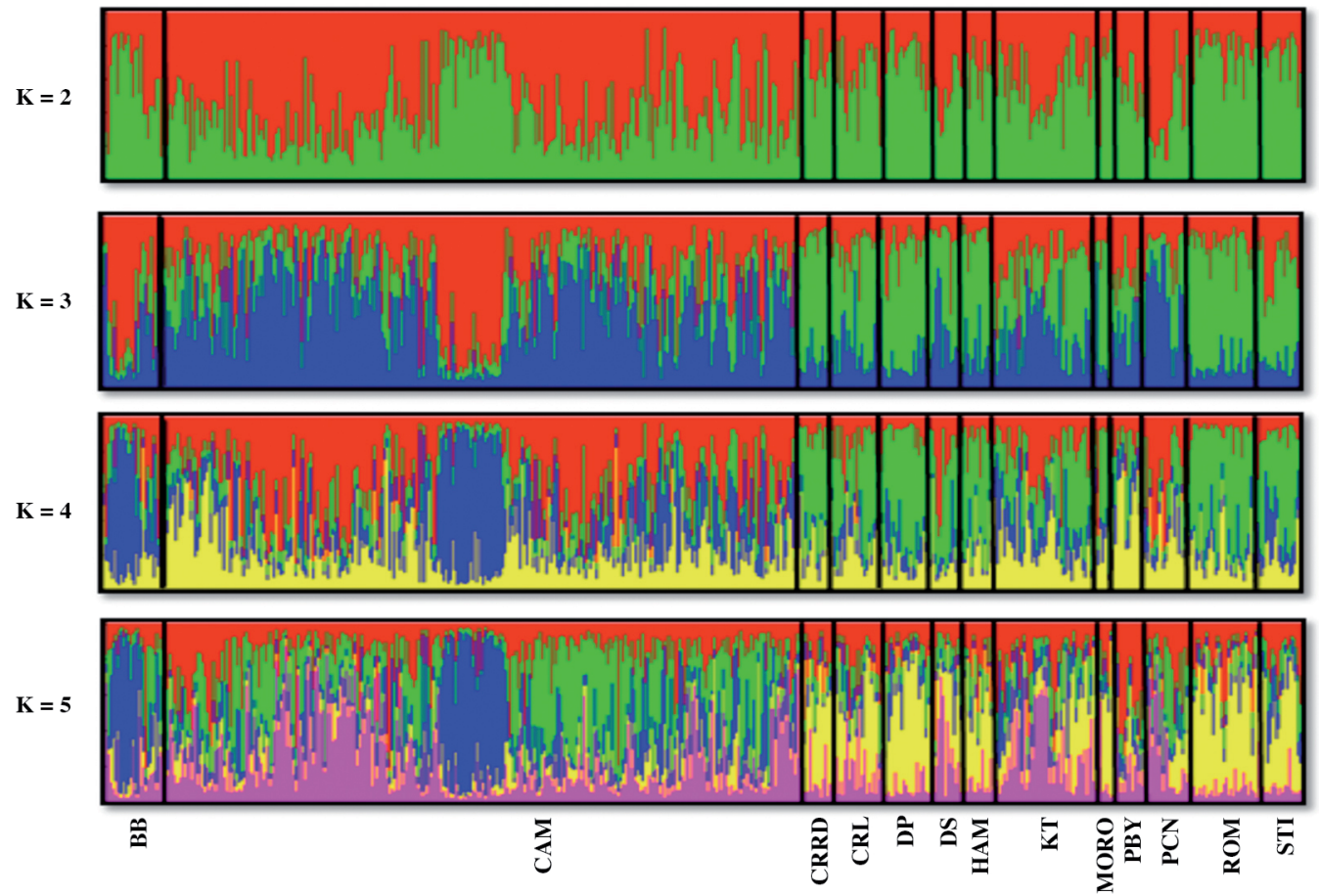

BB: Blackbelly; CAM: Camuro; CRRD: Corriedale; CRL: Criolla de Lana; DP: Dorper; DS: Dorset; HAM: Hampshire;

KT: Katahdin; MORO: Moro Colombiano; PCN: Persian Black Head; PBY: Pelibuey; ROM: Romney Marsh;

STI: Santa Inés.

breeds that live in America today. The second population would be made up by the wool sheep brought from Europe about 500 years ago (mainly 'Churra' and 'Manchego') during the time of the conquest and colonization, who derived the current creole wool breeds present in Colombia today (Pastrana and Calderón, 1996). The last ancestral group could be comprised by the European breeds that have been introduced to the country after colonization in order to make genetic improvement in both wool and hair creole sheep.

Overall, the analysis of phylogenetic groups and structures in the population shows a complex genetic structure of sheep breeds in Colombia, which are influenced by the reproductive and productive management that has been given to them, the geographical distribution throughout the national territory and the historical migration patterns from sheep that have accompanied human migrations, trade and colonization routes throughout history.

\section{CONCLUSIONS}

In conclusion, all 13 breeds evaluated in the project had a high genetic diversity for the 11 microsatellite loci evaluated because none were monomorphic, presented a large number of alleles and high polymorphic information content (PIC).

The combination of the 11 microsatellites used in this project is an effective method to assign parenthood in different sheep breeds in the country, with a higher combined exclusion probability than $99.99 \%$.
All sheep breeds evaluated in this research project showed some degree of heterozygous deficiencies in their population which is mainly attributed to the inbreeding and the presence of substructure in the sheep populations (Wahlund effect). As we discussed, in many of the farms visited the animals are maintained under traditional production systems which have no control in the cross-breeding of animals which reduces heterozygosity in the populations.

Finally, this study contributes to understand the genetic structure and molecular characterization of the Colombian sheep population. To protect creole sheep breeds effectively, the genetic diversity of the populations should be included in decisions for future conservation plans of national genetic resources.

\section{ACKNOWLEDGEMENT}

We would like to thank the Committee for Development of the Investigation (Project Code CODI 2012-5019) and the research group in Genetics, Animal Breeding and Modeling (CODI UdeA Code E01808) for funding the research project. I would also like to thank to COLCIENCIAS for the young researchers and innovators program 2011 of which I was beneficiary. Special thanks go to the sheep farmers who participated in the project for the enormous cooperation that was extended to me for sampling and foremost for the special attention that they offered me during the visits to their farms. 


\section{REFERENCES}

Álvarez, I., J. Capote, A. Traoré, N. Fonseca, K. Pérez, M. Cuervo, et al. 2012. Genetic relationships of the Cuban hair sheep inferred from microsatellite polymorphism. Small Ruminant Research 104:89-93.

Arcos, J., H. Romero, M. Rivera, y E. Riveros (eds.) 2002. Ovinos colombianos de pelo. Alternativa productiva para el sur del departamento del Tolima. 88 p. Corporación Colombiana de Investigación Agropecuaria (Corpoica), Mosquera, Colombia.

Arora R., S. Bhatia, and A. Jain. 2010. Morphological and genetic characterisation of Ganjam sheep. Animal Genetic Resources 46:1-9.

Barrios, C. 2005. Guía práctica de ovinocultura enfocada hacia la producción de carne. Bacom Ltda., Bogotá, Colombia.

Baumung, R., V. Cubric-Curik, and K. Schwend. 2006. Genetic characterisation and breed assignment in Austrian sheep breeds using microsatellite marker information. Journal of Animal Breeding and Genetics 123:265-271

Ben Sassi-Zaidy, Y., F. Maretto, F. Charfi-Cheikrouha, and M. Cassandro. 2014. Genetic diversity, structure, and breed relationships in Tunisian sheep. Small Ruminant Research 119:52-56

Blackburn, H.D., Y. Toishibekov, M. Toishibekov, C.S. Welsh, S.F. Spiller, M. Brown, et al. 2011. Genetic diversity of Ovis aries populations near domestication centers and in the new world. Springer Genetic 139:1169-1178.

Bozzi, R., P. Degl'Innocenti, and P. Rivera Diaz. 2009. Genetic characterization and breed assignment in five Italian sheep breeds using microsatellite markers. Small Ruminant Research 85:50-57

Chen, S.Y., Z.Y. Duan, T. Sha, J. Xiangyu, S.F. Wu, and Y.P. Zhang. 2006. Origin, genetic diversity, and population structure of Chinese domestic sheep. Gene 376:216-223.

Chessa, B., F. Pereira, F. Arnaud, A. Amorim, F. Goyache, I. Mainland, et al. 2009. Revealing the history of sheep domestication using retrovirus integrations. Science 324:532-536.

Ciani, E., R. Ciampolini, M.S. D’Andrea, E. Castellana, F. Cecchi, C. Incoronato, et al. 2013. Analysis of genetic variability within and among Italian sheep breeds reveals population stratification and suggests the presence of a phylogeographic gradient. Small Ruminant Research 112:21-27.

Delgado, J.V., J.M. León, M. Gómez, S. Nogales, y M.E. Camacho. 2009. Las razas ovinas ibéricas y su participación en la colonización de Iberoamérica. p. 18-40. In Delgado, J.V., y S. Nogales (eds.) Biodiversidad ovina iberoamericana. Caracterización y uso sustentable. Luis Barona, Córdoba, España.

Dixit, S.P., N.K. Verma, and R.A.K. Aggarwal. 2012. Genetic diversity and relationship among Indian goat breeds based on microsatellite markers. Small Ruminant Research105:38-45.

Dodgson, J.B., H.H. Cheng, and R.L. Okimoto. 1997. DNA marker technology: a revolution in animal genetics. Poultry Science 76:1108-1113

Egito, A.A., A.S. Mariante, e M.S.M. Albuquerque. 2002. Programa brasileiro de conservação de recursos genéticos animais. Archivos de Zootecnia 51:193-194

Evanno, G., S. Regnaut, and J. Goudet. 2005. Detecting the number of clusters of individuals using the software STRUCTURE: a simulation study. Molecular Ecology 14:2611-2620.

FAO. 1995. Global project for the maintenance of domestic animal genetic diversity (MoDAD). MoDAD, FAO, Rome, Italy. Available at http://agtr.ilri.cgiar.org/agtrweb/Documents/ Library/docs/agri34_project.pdf (accessed December 2014).

FAO. 2011. Molecular genetic characterization of animal genetic resources. FAO Animal Production and Health Guidelines nr 9. 100 p. FAO, Rome, Italy.
Gornas, N., C. Weimann, and A. El Hussien. 2011. Genetic characterization of local Sudanese sheep breeds using DNA markers. Small Ruminant Research 95:27-33.

Guo, J., L.X. Du, Y.H. Ma, W.J. Guan, H.B. Li, Q.J. Zhao, et al. 2005. A novel maternal lineage revealed in sheep (Ovis aries). Animal Genetics 36:331-336.

Goudet, J. 2002. FSTAT (version 2.9.3.2): a program to estimate and test gene diversities and fixation indices. F-statistics. Journal of Heredity 86:485-486.

Kantanen, J., I. Olsaker, and S. Adalsteinsson. 1999. Temporal changes in genetic variation of north European cattle breeds Animal Genetics 30:16-27.

Kayang, B.B., M. Inoue-Murayama, and T. Hoshi. 2002. Microsatellite loci in Japanese quail and cross-species amplification in chicken and guinea fowl. Genetics Selection Evolution 34:233-253

Kim, K.S., J.S. Yeo, and C.B. Choi. 2002. Genetic diversity of north-east Asian cattle based on microsatellite data. Animal Genetics 33(3):201-204

Kugonza, D.R., H. Jianlin, and M. Nabasirye. 2011. Genetic diversity and differentiation of Ankole cattle populations in Uganda inferred from microsatellite data. Livestock Science $135: 140-147$

Li, X., K. Li, and B. Fan. 2000. The genetic diversity of seven pig breeds in China estimated by means of microsatellites. AsianAustralasian Journal of Animal Sciences 13:1193-1195.

Li, M., I. Tapio, J. Vilkki, Z. Ivanova, T. Kiselyova, N. Marzanov, et al. 2007. The genetic structure of cattle populations (Bos taurus) in northern Eurasia and the neighbouring Near Eastern regions: implications for breeding strategies and conservation. Molecular Ecology 16:3839-3853.

McClean, L., L. Waterman, and C. Roberts. 2011. Genetic analysis of three populations of Barbados black belly sheep at microsatellite loci. Journal of Agricultural Science and Technology 1:1187-1191.

Martínez, R., R. Vásquez, y H. Ballesteros. 2010. El ovino criollo en Colombia, conservación, caracterización y evaluación de la variabilidad genética.p. 235-261.In Delgado, J.V., y B.S. Nogales (coord) Biodiversidad ovina iberoamericana. Caracterización y uso sustentable. Servicios de Publicaciones de la Universidad de Córdoba, Córdoba, España.

Nei, M. 1987. Molecular evolutionary genetics. Columbia University Press, New York, USA.

Ochipinti,G.,L.Núñez,C.Cazal,A.Samudio,L.Castro,L.Ramírez, et al. 2012. Diversidad genética en ovejas de las humedades de la región Oriental del Paraguay. Actas Iberoamericanas de Conservación Animal 2:227-230

Park, S.D.E. 2001. Trypanotolerance in West African cattle and the population genetic effects of selection. PhD thesis. University of Dublin, Dublin, Ireland.

Pastrana, R., y C. Calderón. 1996. El ovino criollo colombiano. p. 65-71. Los animales domésticos criollos y colombianos en la producción pecuaria nacional. Instituto Colombiano Agropecuario (ICA), Bogotá, Colombia.

Peakall, R., and P.E. Smouse. 2012. GenAlEx 6.5: genetic analysis in Excel. Population genetic software for teaching and researchan update. Bioinformatics 28:2537-2539.

Pritchard, J.K., M. Stephens, and P. Donnelly. 2000. Inference of population structure using multilocus genotype data. Genetics 155:945-959.

Quiroz, J., A. Martínez, V. Landi, L. Zaragoza, R. Martínez, G. Perezgrovas, et al. 2007. Relación genética de la raza ovina de Chiapas con algunas razas ovinas españolas. Archivos de Zootecnia 56:441-447

Rousset, F. 2008. Genepop'007: a complete reimplementation of the Genepop software for Windows and Linux. Molecular Ecology Resources 8:103-106. 
Sodhi, M., M. Mukesh, and S. Bhatia. 2006. Characterizing Nali and Chokla sheep differentiation with microsatellite markers. Small Ruminant Research 65:185-192.

Sollero, B.P., S.R. Paiva, D.A. Faria, S.E.F. Guimarães, S.T.R. Castro, et al. 2008. Genetic diversity of Brazilian pig breeds evidence by microsatellite markers. Livestock Science 123:8-15.

Soma, P., A. Kotze, J.P. Grobler, and J.B. Van Wyk. 2012. South African sheep breeds: Population genetic structure and conservation implications. Small Ruminant Research 103:112-119.

Souza, C.A., S.R. Paiva, and C.M. McManus. 2012. Genetic diversity and assessment of 23 microsatellite markers for parentage testing of Santa Ines hair sheep in Brazil. Genetics and Molecular Research 8:1217-1229.

Tamura, K., G. Stecher, D. Peterson, A. Filipski, and S. Kumar. 2013. MEGA6: Molecular Evolutionary Genetics Analysis Version 6.0. Molecular Biology and Evolution 30:2725-2729.

Tapio, M., M. Ozerov, I. Tapio, M.A. Toro, N. Marzanov, M. Cinkulov, et al. 2010. Microsatellite-based genetic diversity and population structure of domestic sheep in northern Eurasia. BMC Genetics 10:11-76.
Tolone, M., S. Mastrangelo, A.J.M. Rosa, and B. Portolano. 2012. Genetic diversity and population structure of Sicilian sheep breeds using microsatellite markers. Small Ruminant Research 102:18-25.

Weir, B.S., and C. Cockerham. 1984. Estimating $F$-statistics for the analysis of population structure. Evolution 38:1358-1370.

Yang, C., X. Zhu, and X. Sun. 2008. Development of microsatellite markers and their utilization in genetic diversity analysis of cultivated and wild populations of the mud carp (Cirrhina molitorella). Journal of Genetics and Genomics 35(4):201-206.

Zhong, T., J. Han, and J. Guo. 2010. Genetic diversity of Chinese indigenous sheep breeds inferred from microsatellite markers. Small Ruminant Research 90:88-94.

Zuccaro, A., S. Bordonaro, A. Criscione, M. Guastella, G. Perrotta, M. Blasi, et al. 2008. Genetic diversity and admixture analysis of Sanfratellano and three other Italian horse breeds assessed by microsatellite markers. Animal 2:991-998. 